\title{
Cities and Health: History, Approaches, and Key Questions
}

\author{
David Vlahov, PhD, Emily Gibble, Nicholas Freudenberg, DrPH, and Sandro Galea, MD, DrPH
}

\begin{tabular}{|c|c|}
\hline \multicolumn{2}{|c|}{ Abstract } \\
\hline $\begin{array}{l}\text { The majority of the world's population will live in cities in } \\
\text { the next few years, and the pace of urbanization world- } \\
\text { wide will continue to accelerate over the coming decades. } \\
\text { Such a dramatic demographic shift can be expected to } \\
\text { have an impact on population health. Although there has } \\
\text { been historic interest in how city living is associated with } \\
\text { health, this interest has waxed and waned and a cogent } \\
\text { framework has yet to evolve that encompasses key issues } \\
\text { in urban health. In this article, the authors discuss three } \\
\text { alternate approaches to the study of urban health today; } \\
\text { these include considering urban health from the perspec- } \\
\text { tive of a presumed urban health penalty, from an urban }\end{array}$ & $\begin{array}{l}\text { sprawl perspective, and more comprehensively, consider- } \\
\text { ing how urban living conditions may be associated with } \\
\text { health. The authors also propose three key questions that } \\
\text { may help guide the study and practice of urban health in } \\
\text { coming decades. These include considering what specific } \\
\text { features of cities are causally related to health, the extent } \\
\text { to which these features are unique to a particular city or } \\
\text { are different between cities, and ultimately, to what ex- } \\
\text { tent these features of cities are modifiable in order to allow } \\
\text { interventions that can improve the health of urban } \\
\text { populations. } \\
\text { Acad Med. 2004; } 79: 1133-1138 \text {. }\end{array}$ \\
\hline
\end{tabular}

$\mathrm{T}$ The majority of the world's population will live in cities in the next few years, and the pace of urbanization worldwide will continue to accelerate over the coming decades. ${ }^{1}$ It has been suggested that urbanization was the single most important demographic change to face populations worldwide during the 20th century. ${ }^{2}$ Therefore, considering the implications of this phenomenon for health is becoming increasingly important.

Academic interest in the study of urban health, or how cities may affect health, has waxed and waned over the past few decades. Seminal research in the first half of the 20th century $^{3,4}$ focused attention on the possible relationship between characteristics of the urban environment and health. At the same time, there have been increasing efforts

Dr. Vlahov is director, Ms. Gibble is a research assistant, and Dr. Galea is associate director, all at the Center for Urban Epidemiologic Studies, New York Academy of Medicine, New York, New York. Dr. Freudenberg is professor and director of the Program in Urban Public Health at Hunter College, City University of New York.

Correspondence should be addressed to Dr. Galea, Center for Urban Epidemiologic Studies, New York Academy of Medicine, 1216 Fifth Avenue, New York, NY 10029; telephone: (212) 822-7378; e-mail: 〈sgalea@nyam.org〉. to understand how social and economic factors that are exogenous to the individual may shape health. ${ }^{5-7}$ Some of this thinking can usefully be applied to considerations about the health of urban populations.

Cities are more than the conglomeration of persons who have individual risk factors and health care needs; the perspective taken here is that factors beyond the individual are important determinants of health, including the social and physical environment and systems of health care access. The social environment includes formal and informal networks and social support structures as well as civic organizations, markets, and political structures. The physical environment includes city planning of public space and buildings as well as the quality of air, water, food handling, noise, and transportation. Academic physicians with a commitment to health in cities can contribute to this knowledge base and participate in a broader array of interventions to prevent disease and promote health in urban populations. In this article, we will first briefly discuss the evolution of historic thought about health in cities, summarize three alternate approaches to the study of urban health today, and propose three key questions that may help guide the study and practice of urban health in coming decades. 


\section{Thinking about Cities and Health: A Brief HISTORY}

Researchers and scholars have long considered the study of how cities may shape health an important area of inquiry. Writers from several eras in Western European history considered cities (or urban living) to be detrimental to health, and in many ways, for much of history, cities were characterized by features that were unquestionably linked to poor health. ${ }^{8}$ In 19th-century Europe and America, infectious diseases were rife and have been attributed to unsafe water, improper waste management (especially with poor drainage and unpaved streets), poor food handling, crowded unventilated housing, and a concentration of foreign and domestic commerce that provided introduction of pathogens especially in port cities. ${ }^{9}$ As cities assumed a greater role in the life of European countries, population density, numbers of marginalized populations, pollution, and crime frequently increased, and health became worse within many countries' cities than in nonurban areas. ${ }^{2,10-12}$ Some noted that the rate of urbanization rather than city size was the most powerful predictor of mortality, presumably because this was an indicator of population influx outstripping resources. ${ }^{9}$ Although published data are less readily available, health in cities was also worse than it was in nonurban areas in Asia. ${ }^{13,14}$

While an emerging group of public health practitioners in the 18th and 19th century was beginning to make connections between urban living conditions and health and disease, writers, commentators, and social theorists were articulating how social and economic factors external to the individual could play a role in shaping individual well-being. For example, Jean Jacques Rousseau's work was influential in introducing to Western thinking an appreciation of the role of place and institutions in shaping health and well-being. ${ }^{15}$ Emile Durkheim ${ }^{16}$ provided influential insights about the role of norms and the function of society coincident with the growth of urban living and industrial conditions in cities in the 19th century. Contemporaneously, Ferdinand Tonnies, ${ }^{17}$ a German sociologist, described the rural-urban transition and the increasing unpredictability of urban life that he thought may have an effect on mental and physical health.

Complementing the work of social theorists, poets, and writers provided some of the most eloquent historical testaments to the role of cities in the 19th century and how they may have influenced health. For example, David Copperfield, ${ }^{18}$ the protagonist of Charles Dickens' most autobiographical novel, encounters a city that welcomes "misery ... houselessness ... hunger, rages, tempest, and beggary." James Joyce's Dubliners describes a city in turmoil, including its politics and industry, and a dreary landscape that take a hold on mental health and well-being of the Dublin residents. ${ }^{19}$
However, the urban environment in many Western cities improved dramatically from the mid-19th century through the early 20th century, and coincident with this improvement the health of urban populations also improved. Recent analyses have suggested that the improvement in survival among urban residents was due to a wide range of factors including sanitary reform such as paved streets, construction of sewers, disinfection of water, pasteurization, improvements in nutrition, surveillance and quarantine or isolation of sick individuals, and from an epidemiologic evolutionary perspective, changes in virulence of infections (e.g., scarlet fever) and progressively more immunized populations. ${ }^{9,20,21}$ In Europe, one historical analysis showed that for much of the 19 th century, infant mortality rates in Imperial Germany were higher in urban areas than they were in nonurban areas. However, with sanitary reforms, there was a dramatic improvement in infant mortality rates in urban areas starting in the 1870 s that preceded a comparable decline in mortality in the rest of the country. ${ }^{22}$ Today, health is better in cities than in rural areas in many Western countries. ${ }^{23,24}$ Also, global public health organizations have begun to contend with issues such as sanitation, nutrition, infectious disease, housing, and access to health care that contribute to improved health of urban residents in developing countries. ${ }^{25,26}$ For example, since the 1970s, the World Health Organization has been paying increasing attention to urban health development in many of its technical programs, ${ }^{27}$ and programs such as Healthy Cities 2010 aim to work with local governments to improve living conditions in cities. ${ }^{28}$

\section{Approaches to Urban Health}

The recent resurgence of interest in urban health has been expressed in different ways each with concepts that result in conflicting agendas. Chief among these concepts has been the formulation of urban health under the rubric of the "urban health penalty," which posits that cities concentrate poor people and expose residents to unhealthy environments leading to a disproportionate burden of poor health (one can consider recent movements toward studying "inner-city health" as related to this formulation). The departure of the middle class and jobs to the surrounding suburbs in the past 50 years within the United States as well as in many other Western countries lead to concentrated urban poverty and increased racial segregation; the result was to leave cities with diminished capacity to meet the needs of increasingly impoverished populations. ${ }^{29}$ By the late 20th century, U.S. and some European cities had higher rates than their respective nonurban areas of HIV infection, substance abuse, mental illness, infant mortality, asthma, and other conditions. ${ }^{30}$ These disparities led to a resurrection of the earlier concept 
of "urban health penalty." 30,31 Considering issues related to urban health within an "urban health penalty" rubric draws specific attention to the poor health conditions that persist in many inner cities, ${ }^{32,33}$ describes the resulting inequalities in health, ${ }^{34}$ and points to the necessity of improving health conditions, particularly among disadvantaged urban populations. However, this approach tends to equate "urbanness" with issues of disadvantage and urban health becomes synonymous with conditions among the minority poor of the inner cities. In so doing, this approach fails to recognize that cities have many positive aspects, such as proximity of social support and health care structures. In addition, this approach does not lead us to consider the specific characteristics of cities that may be associated with poor health and that it is a multitude of factors (including, but not limited to poverty) that account for urban population health.

More recently, there has been much attention paid to "urban sprawl," a concept that has developed to focus on the consequences of the diffusion of urban populations outside central cities. Motivated by the rapid suburbanization of U.S. and European cities in the past 50 years, this approach highlights the adverse health effects of urban growth into outlying areas. These effects include increasing automobile pollution and accidents, sedentary lifestyles, the rise in obesity and diabetes, increased social isolation, and the breakdown of social capital. ${ }^{35}$ By considering urban health beyond the inner city, this approach improves on the urban health penalty approach and raises important questions related to sustainable infrastructure development and the health of populations in sprawling, densely populated areas. However, the urban sprawl approach overlooks the inner city as a valid and critical focus of interest and by necessity forces attention on one characteristic of urban areas-sprawl-to the detriment of other features of the urban social and physical environment that are also likely to contribute to population health, even in sprawling suburbs.

In the past few years more attention has been paid to urban health in its totality, and a few frameworks have been proposed that discuss how features of urban living may affect population health. While some of these frameworks are tightly focused, such as those that have considered how features of the built physical environment may affect population health, ${ }^{35-37}$ a recent framework has discussed urban health in the larger context. ${ }^{38}$ This conceptual framework views health in cities as a function of individual factors influenced by local social and physical environment factors, which in turn are influenced by municipal and national policy, and markets and international trends, including immigration. ${ }^{38}$ This framework is an extension to the thinking proposed in this article. However, there remains little agreement whether urban health should be considered a unique discipline in and of itself. ${ }^{39-41}$ In fact, it has been argued that urban health represents too broad a mandate to be the purview of a single discipline. ${ }^{40,42}$ Historically in academic medicine, these issues were raised in departments of social medicine; now, health of urban populations is a topic that can more broadly include the fields of medicine, allied health including nursing and social work, public health, urban planning, social sciences, and law, to name a few. ${ }^{42}$ We argue that the growing importance of cities, coupled with the demonstrated historic and current relations of various features of the urban context and population health, suggests that focused attention, both on defining urban health as a field of inquiry and considering specific features of the urban social, economic, and physical context that may affect health, has potential to guide interventions (with rigorous evaluations) that can dramatically improve the health of populations in the 21 st century. We offer below three questions that may help guide urban health research.

\section{Three Key Questions in Considering How Cities May Affect Health}

Modern research methods have allowed greater refinement on the question of how city living and urbanization may (or may not) affect health. However, if one were to assess the bulk of the research on the relation between urban living and health, it quickly becomes evident that this work has generally produced conflicting results. For example, while higher rates of mental illness have been documented in urban compared with rural areas in the United Kingdom, ${ }^{43}$ urbanrural differences in mental health have not been observed in Canada, ${ }^{44}$ even though the studies used comparable methodology. In the United States, some studies have documented urban-rural differences in mental health ${ }^{45}$ while others reported no differences. ${ }^{46,47} \mathrm{~A}$ study in Taiwan found a lower prevalence of mental health problems in urban compared with rural areas. ${ }^{48}$ Studies of the prevalence of heart disease and cancer by urban versus rural regions have similarly shown inconsistencies (e.g., Yamamoto and Watanabe's 2001 study $^{49}$ ).

Such comparisons, however, suffer from the oversimplification of what likely is a complicated relationship. Cities may affect health, but the net relationship between cities and health is likely to be a combination of the range of factors that may matter for the health of urban populations. For example, living in a particular city may bring with it multiple factors that may adversely affect health, but also several that may result in good health. So, a particular city may have more violence and air pollution than surrounding areas but also have better social supports and social services. Clearly then, considering how a "city" may affect overall individual "health" is a simplification of a larger and more complicated 
question. While a full discussion of the factors that may affect health in cities is beyond the scope of this article (we refer to reader to other work, including Galea et $\mathrm{al}^{38}$ and Galea and Vlahov ${ }^{42}$ for a fuller discussion of these factors), we discuss here some of the key questions we think are important if we are to improve our understanding of health in cities.

\section{What Are the Specific Features of Cities That Are Causally Related to Health?}

Much of the academic work that historically has contributed to the study of "urban health" has involved comparisons between the health of persons in urban areas and of persons in nonurban areas, or alternately, comparisons of the health of persons in different cities. This work then isolates the city itself as the entity of interest and helps identify the characteristics of the city as a whole that may be associated with population health. Although this work has been useful historically, particularly in raising awareness of the importance of thinking about health in cities, it does not allow a nuanced understanding of the characteristics that actually may be the determinants of health in cities.

A growing body of work is using an "intraurban" perspective. This perspective considers characteristics of urban areas that are associated with health and typically focuses on spatial groupings of individuals (typically conceived as "neighborhoods," although several studies assess the contribution of administrative groupings that are not necessarily meaningful to residents as neighborhoods) and considers the role of community of residence within an urban area on individual health (e.g., Weich and colleagues in 2002,50 Reijneveld in 1998, ${ }^{51}$ and Yen and Kaplan in $1999^{52}$ ). The growing use of multilevel modeling techniques in epidemiology, which allows researchers to disentangle effects due to individual versus neighborhood characteristics, has made these studies both more common and methodologically more robust, and provides an opportunity for deeper insights into how features of the urban environment may influence health. For example, considering how urban living may affect mental health, the extent to which depression is related to socioeconomic status or to the quality of housing is an open question. Reijneveld in 1998, ${ }^{51}$ using a random sample of adult residents in Amsterdam, failed to observe a relation between living in socioeconomically disadvantaged urban neighborhoods and residents' mental health. In a crosssectional study, Weich et al. in $2002^{50}$ found that persons living in poor-quality physical environments were more likely to report symptoms consistent with depression after accounting for individual characteristics. A recent study corroborating these two observations used a randomized, controlled trial in which families were moved from public housing in high-poverty neighborhoods to private housing in nonpoor neighborhoods in New York City. ${ }^{53}$ This experimental study showed that both parents and children who were moved to the better housing and better neighborhoods reported fewer psychological distress symptoms than did control families who were not moved (although the difference in mental health was noted in boys but not in girls). Thus, while a relatively nascent area of research, multilevel analyses assessing relations between characteristics of urban environments (e.g., housing) and individual health hold promise in being able to identify specific characteristics of the urban environment that may affect health.

\section{To What Extent Are Features Unique to a Particular City or Different Between Cities?}

Identifying the characteristics of urban areas that may be associated with health is a first step in understanding the determinants of population health in cities. A necessary, but not sufficient, next step is recognizing the extent to which these characteristics are generalizable across cities and can, as such, form the basis for generalizable inference and, eventually, intervention. One of the primary drawbacks to multilevel analyses that assess the relation of intraurban differences and health is that it may be difficult to generalize findings from one city to urban areas more broadly. For example, the observation in one study that the physical quality of residences in London is inversely associated with the likelihood of depression among urban residents ${ }^{50}$ may not necessarily be relevant in another urban context where the social environment (e.g., social networks, civic organizations, social capital) plays an equally important role in shaping individual mental health. This observation is a reflection of the complexity of the factors that may shape mental health in cities and of the limitations of extant methods in fully assessing how urban living conditions may affect health. It will be important for researchers and practitioners alike to have access to a catalog of observations detailing how specific characteristics of the urban physical and social environment shape health and how these observations may extend to different urban contexts. In order to move in this direction we must consider both the context in which their studies were carried out and provide discussion of the extent to which this context is generalizable. For example, a study that considers how quality of neighborhood housing may shape asthma morbidity ${ }^{54,55}$ would do well to also entertain the role of medical and preventive care for asthma in a given city. We note that this is particularly important in the international context, where the primary determinants of health in cities may well be substantially 
different cross-nationally. Assessing the extent to which associations between urban characteristics and health in one urban context are generalizable across cities suggests the need for researchers to think beyond a typical "risk factor" model, where individual risk factors, albeit potentially at multiple levels, are considered in relation to particular diseases. Although we recognize that such an approach inevitably complicates both the design of the research as well as its interpretation, there has long been a call for a greater appreciation of complexity in epidemiologic research ${ }^{56-58}$ and the generation of causal inference ${ }^{59}$; we argue that such considerations are particularly important in the study of urban health.

\section{To What Extent Are Features of Cities Modifiable?}

Although the extent to which specific features of cities are modifiable is not a sine qua non of urban health research, in the context of a complicated field of inquiry where multiple factors may contribute equally to the causation of health and disease, it is important to focus inquiry on areas that may be related to potential intervention to improve health in cities. When considering urban health within a larger framework, considering how factors such as international trends and municipal factors affect the social and physical environments that proximally define the urban context, ${ }^{38}$ it is reasonable to argue that all features of the urban context to a lesser or greater extent are modifiable. However, this generalization belies the fact that specific features may be more easily modifiable, with far greater, relatively short-term improvement in urban population health, than others. For example, the observation that a substantial proportion of morbidity in a given urban area is associated with poor sanitation and inadequate clean water supply, problems that are commonly key determinants of health in developing world cities, may strongly suggest focused interventions that are achievable given an infusion of adequate resources. ${ }^{60,61}$ Conversely, the observation that social norms around substance use place specific urban populations at risk for drug abuse and dependence may require a far larger commitment in the form of a multilevel intervention to affect lasting change. ${ }^{62}$

\section{CONCLUSION}

As cities grow worldwide and as more of the world's population lives in cities, there has been a return of interest in city living and how it may affect health. However, little consensus exists about the best approach to considering urban health research and what questions such a field of inquiry should address. We suggest that considering urban health in its totality including the social, economic, and physical characteristics of cities that may affect health has the potential to improve our understanding of population health in cities and to guide effective interventions. Considering the key questions presented here may be a useful guide for academic researchers and practitioners interested in understanding the determinants of health in urban populations.

This article was funded in part by cooperative agreement U48/CCU 209663 with the Centers for Disease Control and Prevention and by grants R01 DA 017642-01 and DA 013146-51 from the National Institutes of Health, U.S. Department of Health and Human Services.

\section{REFERENCES}

1. Brockerhoff MP. An urbanizing world. Pop Bull. 2000;55(3):3-4.

2. McMichael AJ. Urbanization and urbanism in industrialized nations, 1850-present: implications for health. In: Schell LM, Ulijaszek SJ (eds). Urbanism, Health, and Human Biology in Unindustrialized Countries. Cambridge: Cambridge University Press, 1999:21-45.

3. Butler EB. Women and the Trades, Pittsburgh, 1907-1908; The Pittsburgh Survey; Findings in Six Volumes. New York: Charities Publication Committee, 1909.

4. Faris REL, Dunham HW. Mental Disorders in Urban Areas. Chicago: The University of Chicago Press, 1939.

5. Evans RG, Stoddart GL. Producing health, consuming health care. Soc Sci Med. 1990;31:1347-63.

6. Blum HL. Planning for Health: Developmental Application of Social Change Theory. New York: Human Sciences Press, 1974.

7. Travis JW. Wellness for Helping Professionals. 3rd ed. Mill Valley, CA: Wellness Associates, 1977.

8. Krupat E. Cities and People. Cambridge: The Cambridge University Press, 1985:99:

9. Grob GN. The Deadly Truth: A History of Disease in America. Cambridge: Harvard University Press, 2002.

10. Lund VK. The Healthy Communities Movement: bridging the gap between urban planning and public health $\langle\mathrm{http} / /$ www.asu.edu/caed/ proceedings99/LUND/LUND.HTM $\rangle$. Accessed 17 August 2004. Arizona State University, 1999.

11. Sheard S, Power H. 2000. Body and City: Histories of Urban Public Health. Aldershot: Ashgate, 2000.

12. Glaab CN, Brown TA. A History of Urban America. London: CollierMacmillan Limited, 1967.

13. Peters J. Urbanism and health in industrialized Asia. In: Schell LM, Ulijaszek SJ (eds). The Urbanism, Health and Human Biology in Industrialized countries. Cambridge: Cambridge University Press, 1999: 159-63.

14. Lee L. The current state of public health in China. Annu Rev Public Health 2004;25:327-39.

15. Marsella AJ. Urbanization, mental health and psychosocial well-being: some historical perspectives and considerations. In: Harpham T, Blue I (eds). Urbanization and Mental Health in Developing Countries. UK: Aldershot, 1995:3-14.

16. Durkheim E. The Division of Labor in Society (1893). Simpson G (trans). New York: The Free Press, 1947.

17. Tonnies F. Gemeinschaft und Gesellschaft. (1887) [Community and Society]. Loomis CP (trans-ed). East Lansing: Michigan State University Press, 1957:223-31.

18. Dickens C. David Copperfield. London: Harper, 1850.

19. Joyce J. Dubliners. London: Grant Richards, 1914. 
20. Griscom J. Sanitary Condition of the Laboring Population of New York. New York: Harper, 1845.

21. Hamlin C. Public Health and Social Justice in the Age of Chadwick: Britain 1800-1854. Cambridge: Cambridge University Press, 1998.

22. Vogele JP. Urban infant mortality in Imperial Germany. Soc Hist Med. 1994; 7:401-25.

23. Population Reference Bureau. Transitions in world population. Pop Bull 59(1);2004 〈http://www.prb.org/Template.cfm?Section=Population Bulletin1\&template $=/$ ContentManagement $/$

ContentDisplay.cfm\&ContentID=10610). Accessed 20 August 2004. Washington, DC, March 2004.

24. Eberhardt MS, Ingram DD, Makuc DM. Health, United States, 2001 with urban and rural health chartbook /http://www.cdc.gov/nchs/ hus.htm〉. Accessed 17 August 2004. National Center for Health Statistics, Hyattsville, MD, 2004.

25. Seager J. Research on urban health: priorities and approaches. In: Harpham T, Tanner M (eds). Urban Health in Developing Countries: Progress and Prospects. New York: St. Martin's Press, 1995:64-81.

26. Satterthwaite D (ed). Sustainable Cities. London: Earthscan, 2001.

27. Goldstein G, Rossi-Espagnet A, Tabibzadeh I. How the World Health Organization supports urban health development. In: Harpham T, Tanner M (eds). Urban Health in Developing Countries: Progress and Prospects. Earthscan: London,1995:110-122.

28. Healthy cities and urban governance $\langle$ http://www.who.dk/healthy-cities $\rangle$. Accessed 17 August 2004. World Health Organization Regional Office for Europe, Copenhagen, Denmark, 2004.

29. Wilson WJ. When Work Disappears: The World of the New Urban Poor. New York: Knopf, 1996.

30. American College of Physicians. Inner-city health care. Ann Intern Med. 1997;127:485-90.

31. Vlahov D, Galea S. Urbanization, urbanicity, and health. J Urban Health. 2002;79(4 suppl 1):S1-12.

32. Power H, Sheard S (eds). Body and City: Histories of Urban Public Health. London: Ashgate, 2001.

33. Rosen G. Preventive Medicine in the United States, 1900-1975: Trends and Interpretations. New York: Science History Publications, 1975.

34. Geronimus AT, Bound J, Waidmann TA, et al. Excess mortality among blacks and whites in the United States. N Engl J Med. 1996;335: 1552-8.

35. Frumkin H. Urban sprawl and public health. Public Health Rep. 2002;117:201-17.

36. Northridge ME, Sclar ED, Biswas P. Sorting out the connections between the built environment and health: a conceptual framework for navigating pathways and planning healthy cities. J Urban Health. 2003;80:556-68.

37. Schulz A, Northridge ME. Social determinants of health and environmental health promotion. Health Educ Behav. 2004;31:455-71.

38. Galea S, Freudenberg N, Vlahov D. Cities and population health: a framework for studying how urban living affects health drawing on the US experience. Soc Sci Med [in press].

39. Vlahov D, Galea S. Urban health: a new discipline. Lancet. 2003;362: 1091-2.

40. Guyer B, Gibbons MC. Urban health: discipline or field-does it matter? J Urban Health. 2004;2:165-8.

41. Harpham T. Urban Health: A future focus for career development. J Urban Health. 2004;2:168-70.

42. Galea S, Vlahov D. Urban health: evidence, challenges and directions. Annu Rev Public Health. 2005;26:1-25.
43. Paykel ES, Abbott R, Jenkins R, et al. Noise exposure and public health. Environ Health Perspect. 2002;108(1 suppl):123-31.

44. Parikh SV, Wasylenki D, Goering P, et al. Mood disorders: rural/urban differences in prevalence, health care utilization, and disability in Ontario. J Affect Dis. 1996;38:57-65.

45. Blazer D, George LK, Landerman R, et al. Psychiatric disorders: a rural/urban comparison. Arch Gen Psychiatr. 1985;42:651-6.

46. Blazer DG, Kessler RC, McGonagle KA, Swartz MS. The prevalence and distribution of major depression in a national community sample: The National Comorbidity Survey. Am J Psychol. 1994;151:979-86.

47. Kessler RC, McGonagle KA, Zhao S, et al. Lifetime and 12-month prevalence of DSM-III-R psychiatric disorders in the United States. Arch Gen Psych. 1994;51:8-19.

48. Hwu H-G, Yeh E-K, Chang L-Y. Prevalence of psychiatric disorders in Taiwan defined by the Chinese Diagnostic Interview Schedule. Acta Psychiatr Scandind. 1989;79:136-47.

49. Yamamoto S, Watanabe S. Geographic characteristics and mortality profiles in the JPHC study. Japan public health center-based prospective study on cancer and cardiovascular diseases. J Epidemiol. 2001;11(6 suppl):S8-23.

50. Weich S, Blanchard M, Prince M, Burton E, Erens B, Sproston K. Mental health and the built environment: cross-sectional survey of individual and contextual risk factors for depression. Br J Psychiatry. 2002;180:428-33.

51. Reijneveld SA. Reported health, lifestyles, and use of health care of first generation immigrants in The Netherlands: do socioeconomic factors explain their adverse position? Epidemiol Community Health. 1998;52: 298-304.

52. Yen IH, Kaplan GA. Neighborhood social environment and risk of death: multilevel evidence from the Alameda county study. Am J Epidemol. 1999;149:898-907.

53. Leventhal T, Brooks-Gunn J. Moving to opportunity: an experimental study of neighborhood effects on mental health. Am J Public Health. 2003;93:1576-82.

54. Hynes HP, Brugge D, Osgood ND, et al. Where does the damp come from? J Public Health Policy. 2003;24:401-26.

55. Simon PA, Zeng Z, Wold CM, et al. Prevalence of childhood asthma and associated morbidity in Los Angeles County: impacts of race/ ethnicity and income. J Asthma. 2003;40:535-43.

56. Koopman JS, Lynch JW. Individual causal models and population system models in epidemiology. Am J Public Health. 1999;89:1170-4.

57. Krieger N. Epidemiology and the web of causation: has anyone seen the spider? Soc Sci Med. 1994;39:887-903.

58. Karpati A, Galea S, Awerbuch T, Levins R. Variability and vulnerability at the ecologic level: implications for understanding the social determinants of health. Am J Public Health. 2002;92:1768-72.

59. Cordray DS. Quasi-experimental analysis: a mixture of methods and judgments. New Dir Prog Eval. 1986;31:9-28.

60. Checkley W, Gilman RH, Black RE, Epstein LD, Cabrera L, Sterling CR, Moulton LH. Effect of water and sanitation on childhood health in a poor Peruvian peri-urban community. Lancet. 2004;363:112-8.

61. Heller L, Colosimo EA, Antunes CM. Environmental sanitation conditions and health impact: a case-control study. Rev Soc Bras Med Trop. 2003;36:41-50.

62. Kaplan CP, Napoles-Springer A, Stewart SL, et al. Smoking acquisition among adolescents and young Latinas: the role of socioenvironmental and personal factors. Addict Behav. 2001;26:531. 